\title{
THE ANAESTHETIC MANAGEMENT OF TRACHEO-OESOPHAGEAL FISTULA: A REVIEW OF TEN YEARS' EXPERIENCE
}

\author{
R.K. Calverley, M.D., F.R.C.P.(C) aNd
}

A.E. JohNSTON, M.D., C.M., F.R.C.P.(C), F.A.A.P.

\section{INTRODUCTION}

SURnval rates after surgical correction of tracheo-oesophageal fistula at The Hospital for Sick Children, Toronto, have improved in the 5-year period, 1964 1968, over the immediately preceding 5-year period, 1959-1963. ${ }^{1}$ Several factors influence survival: the type of anomaly, the degree of prematurity, the presence of other congenital anomalies, pulmonary complications, the age at operation, the type of surgical repair, the anaesthetic management and postoperative care.

The records of the cases treated during the 1964-1968 period have been reviewed and comparisons made, where possible, of the effect of these factors on the improved survival rates during this second 5-year period.

\section{TYPE OF ANOMALY}

Tracheo-oesophageal fistula and oesophageal atresia are interrelated anomalies, and tracheo-oesophageal fistula may occur with or without oesophageal atresia. During 1964-1968 a total of 90 cases were treated surgically and during 19591963, 116 cases. $^{1}$ Cases were described as Types 1-5 (Figure 1). The frequency of the types was comparable in the two series (Table I). The commonest anomaly was that in which there was an oesophageal atresia and a fistula between the trachea and the distal segment of the oesophagus [Type 1 or Gross Table C] (Table I).

TABLE I

Tracheo-Oesophageal Fistula with or without Oesophageal ATRESia

\begin{tabular}{|c|c|c|c|c|c|}
\hline & & \multicolumn{2}{|c|}{$1959-1963$} & \multicolumn{2}{|c|}{$1964-1968$} \\
\hline & & No. & $\begin{array}{l}\text { Per cent } \\
\text { of total }\end{array}$ & No. & $\begin{array}{l}\text { Per cent } \\
\text { of total }\end{array}$ \\
\hline $\begin{array}{l}\text { Type } 1 \\
\text { Type } 2\end{array}$ & $\begin{array}{l}\text { (Gross Type C) } \\
\text { (Not included }\end{array}$ & 100 & 86.2 & 76 & 84.4 \\
\hline $\begin{array}{l}\text { Type } 3 \\
\text { Type } 4 \\
\text { Type } 5\end{array}$ & $\begin{array}{l}\text { in review) } \\
\text { (H-Type) }\end{array}$ & $\begin{array}{r}12 \\
3 \\
1 \\
0\end{array}$ & $\begin{array}{r}10.3 \\
2.5 \\
0.9\end{array}$ & $\begin{array}{l}8 \\
7 \\
0 \\
0\end{array}$ & $\begin{array}{l}8.8 \\
7.6\end{array}$ \\
\hline
\end{tabular}

From the Department of Anaesthesia, The Hospital for Sick Children, Toronto, Canada.

-Dr. Calverley is now with the Department of Anaesthesia, Vancouver General Hospital, Vancouver 9, British Columbia, Canada.

Reprint requests to Dr. A.E. Johnston, Department of Anaesthesia, The Hospital for Sick Children, 555 University Avenue, Toronto 101, Canada. 
Twelve cases of Type 2 anomaly in the first series and 8 in the second were excluded from the review by definiiton.
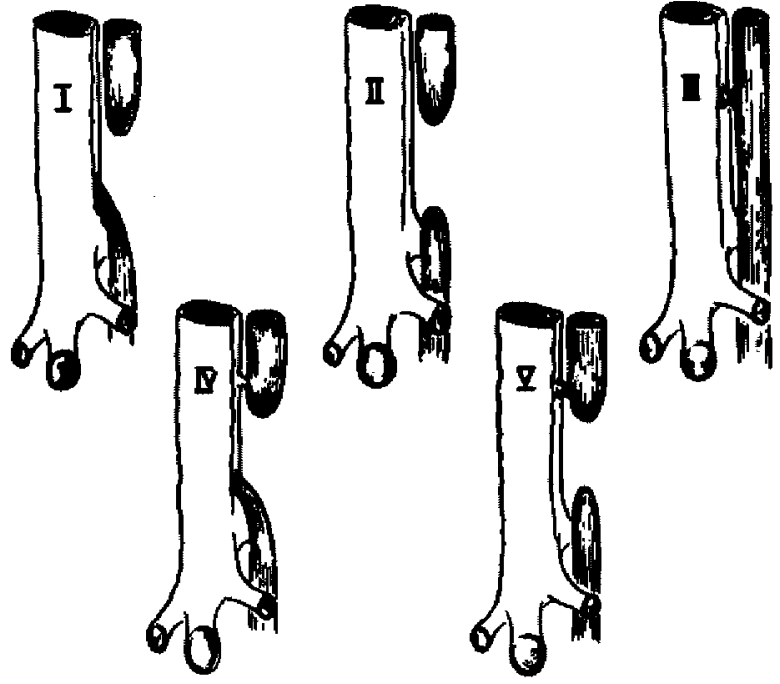

Ficure 1. Diagram showing types of tracheoesophageal fistula and oesophageal atresia.

\section{Preoperative Factors Influencing Survival}

The 3 main preoperative factors influencing survival are associated congenital anomalies, prematurity, and pulmonary complications.

The associated congenital anomalies which might have affected the outcome occurred in 28 (26.9 per cent) cases in the first series and 23 (27.7 per cent) cases in the second series and are listed in Table II. The disparity between the total number of anomalies and the number of patients affected reflects the number of patients with anomalies involving 2 or more systems.

Though the degree of prematurity is not always reflected accurately by the

TABLE II

Associated Congemital Anomalies

\begin{tabular}{lcc}
\hline \multicolumn{1}{c}{ Condition } & $1959-1963$ & $1964-1968$ \\
\hline Laryngo-malacia & 0 & 2 \\
Cardiovascular (VSD Coarctation & 5 & 13 \\
Truncus, PDA etc) & 5 & 5 \\
Multiple gastrointestinal & 6 & 5 \\
Genitourinary (absent kidney) & 10 & 6 \\
Imperforate anus & 6 & 3 \\
Cleft palate & 0 & 3 \\
Hiatus hernia & 0 & 3 \\
Dysplasia of lung & 0 & 1 \\
Hydrocephalus & 1 & 1 \\
Erythroblastosis fetalis & 1 & 6 \\
Mongolism & &
\end{tabular}


birth weight, infants with a birth weight less than $2,500 \mathrm{gm}$ are classified as premature for the purposes of the study. Forty of the 104 cases (38.4 per cent) in the first series and 30 of the 83 cases ( 36.1 per cent) were premature.

Pulmonary complications were reported in only 28 (26.6 per cent) cases in the first series, but in 40 ( 48.2 per cent) cases in the second series.

The incidence of pulmonary complications is related to the time of diagnosis and the age at which surgical correction is undertaken. Aspiration of secretions or feedings from the proximal oesophageal segment results in atelectasis or lobar pneumonia particularly of the (R) upper lobe. Regurgitation of gastric contents through the fistula is more serious and may result in diffuse chemical pneumonitis which is often resistant to treatment.

The advantages of diagnosis before the first feeding are obvious. In the second series 18 of the 28 patients fed prior to diagnosis developed significant pulmonary complications and 5 of the 18 died.

In the first series 74 per cent were operated on within 48 hours of birth and in the second 69.9 per cent (Table III).

The higher reported incidence of pulmonary complications in the second series may result from improved medical recording and more precise application of the criteria suggested by Waterston, Bonham-Carter and Aberdeen: "X-ray opacity or clinical signs limited to one lobe only were labelled moderate pneumonia; changes in both lungs, were grouped as severe pneumonia". ${ }^{2}$

\section{Results}

The survival rate improved by 15 per cent from 63.5 per cent in the $1959-1963$ series to 78.3 per cent in the $1964-1968$ series, but the improvement was more dramatic in the premature group (Tables III and IV).

In the first series the survival rate of premature infants was half that of mature infants, whereas in the second series the survival rate of premature infants was about two-thirds that of mature infants.

TABLE III

SURVIVAL. RATE

\begin{tabular}{lcc}
\hline & $1959-1963$ & $1964-1968$ \\
\hline Total cases & 104 & 83 \\
Survivors & 66 & 65 \\
Survival rate & $63.5 \%$ & $78.3 \%$ \\
\hline
\end{tabular}

TABLE IV

Influence of Prematurity on Survival Rate

\begin{tabular}{lccccc}
\hline \hline & \multicolumn{2}{c}{$<2500 \mathrm{gm}$} & & \multicolumn{2}{c}{$>2500 \mathrm{gm}$} \\
\cline { 2 - 3 } \cline { 5 - 6 } & $1959-1963$ & $1964-1968$ & & $1959-1963$ & $1964-1968$ \\
\hline Total cases & 40 & 30 & & 64 & 53 \\
Survivors & 17 & 18 & & 49 & 47 \\
Survival rate & $42.5 \%$ & $60 \%$ & & $76.6 \%$ & $88.7 \%$ \\
\hline
\end{tabular}


The effect of associated congenital anomalies or pulmonary complications or both on survival were compared for premature and mature infants in the 2 periods (Table V and Table VI). Although the overall survival rate improved in the prematures, the most striking improvement was in prematures without associated anomalies or pulmonary complications (100 per cent survival in 1964-1968). In the second as well as the first series associated anomalies or pulmonary complications lowered the survival rate, particularly when both were present.

TABLE $V$

Survival Rates in Patients $<2500$ gm

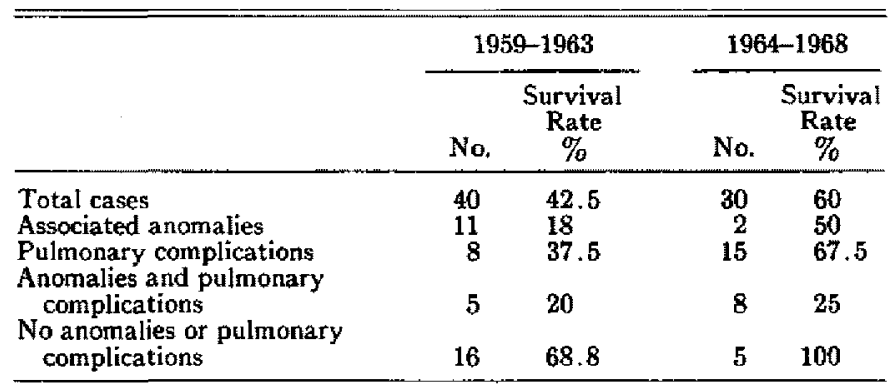

The overall survival rate of mature infants improved, particularly among those without other congenital anomalies or pulmonary complications (Table VI). The survival rate in this group was 100 per cent in the second series. The presence of associated anomalies or pulmonary complications lowered the survival rate particularly if both were present.

TABLE VI

Survival Rates in Patients > 2500 gm

\begin{tabular}{|c|c|c|c|c|}
\hline & \multicolumn{2}{|c|}{$1959-1963$} & \multicolumn{2}{|c|}{$1964-1968$} \\
\hline & No. & $\begin{array}{c}\text { Survival } \\
\text { Rate } \\
\%\end{array}$ & No. & $\begin{array}{c}\text { Survival } \\
\text { Rate } \\
\%\end{array}$ \\
\hline $\begin{array}{l}\text { Total cases } \\
\text { Associated anomalies } \\
\text { Pulmonary complications } \\
\text { Aromalies and pulmonary }\end{array}$ & $\begin{array}{r}64 \\
9 \\
20\end{array}$ & $\begin{array}{l}76.6 \\
44.5 \\
75.0\end{array}$ & $\begin{array}{r}53 \\
8 \\
25\end{array}$ & $\begin{array}{l}88.7 \\
87.5 \\
88.0\end{array}$ \\
\hline $\begin{array}{l}\text { complications } \\
\text { No anomalies or pulmonary }\end{array}$ & 3 & 66.7 & 5 & 60.0 \\
\hline complications & 32 & 87.5 & 15 & 100 \\
\hline
\end{tabular}

To facilitate comparisons with other reported series ${ }^{2-3}$ we reclassified the patients in the 1964-1968 series according to the criteria of Waterston, et al. ${ }^{2}$

Group A - Birth weight over $5 \% \mathrm{lb}$. (2,500 gm and well).

Group B1 - Birth weight $4-5 \% \mathrm{lb}$. (1,800-2,500 gm and well).

Group B2 - Higher birth weight, moderate pneumonia and congenital anomaly.

Group $\mathrm{Cl}-$ Birth weight under $4 \mathrm{lb}$. $(1,800 \mathrm{gm})$.

Group C2 - Higher birth weight and severe pneumonia and severe congenital anomaly. 
Using this classification survival rate was 100 per cent in Groups $A$ and $B$ and 50 per cent in Group Cl + C2 (Table VII).

TABLE VII

Ceasstrtcation

\begin{tabular}{lccccccc}
\hline & & \multicolumn{2}{c}{ Group B } & & \multicolumn{2}{c}{ Group C } \\
\cline { 3 - 4 } \cline { 7 - 8 } & Group A & 1 & 2 & & 1 & 2 \\
\hline Total cases & 15 & 4 & 28 & & 9 & 27 \\
Survivors & 15 & 4 & 28 & & 2 & 16 \\
Survival rate & (per cent) & 100 & 100 & 100 & & 22.2 & 59.2 \\
\hline
\end{tabular}

Preoperattve Management

Diagnosis

Early diagnosis is important so that the anomaly can be corrected surgically before the patient's condition deteriorates.

The classical signs suggesting tracheo-oesophageal fistula with oesophageal atresia are excessive salivation or coughing, choking and cyanosis with the first feeding, or all of these. A soft \#10-12 suction catheter should be passed into the baby's stomach routinely at birth to exclude oesophageal atresia. If the suction catheter cannot be passed into the stomach, the diagnosis may then be confirmed by roentgenogram made after passing a radiopaque catheter into the proximal oesophageal segment (Figure 2). Air in the stomach indicates a fistula between the trachea and distal oesophageal segment. Indeed the stomach may be so distended it interferes with diaphragmatic excursion and causes hypoventilation.

The distance from the centre where correction was undertaken had no effect on survival. In the second series 49.4 per cent of the patients were born in Metropolitan Toronto and 50.6 per cent were born more than 25 miles from Toronto. Four patients transported more than 500 miles before operation survived.

Tracheo-oesophageal fistula without associated oesophogeal atresia (Type III or H-Type fistula) is more difficult to diagnose and is usually not detected until the child is older. Episodes of choking at feeding and repeated "respiratory infections" without obvious cause are the usual clues. The severity of the symptoms and the age at diagnosis will depend on both the size and the obliquity of the fistula. Bronchoscopy may be necessary to confirm the diagnosis.

\section{General Management}

Once the diagnosis is made the aim of management is to prevent further pulmonary complications until surgery can be undertaken.

All oral feedings are stopped and the baby is kept in a semi-upright position to minimize regurgitation of gastric juice through the fistula. The proximal oesophageal segment is sùctioned continuously with a soft rubber catheter to prevent aspiration of naso-pharyngeal secretions.

Fluid and electrolyte depletion are not usually major problems because neonatal fluid requirements are low during the first 24-28 hours of life. Electrolyte 


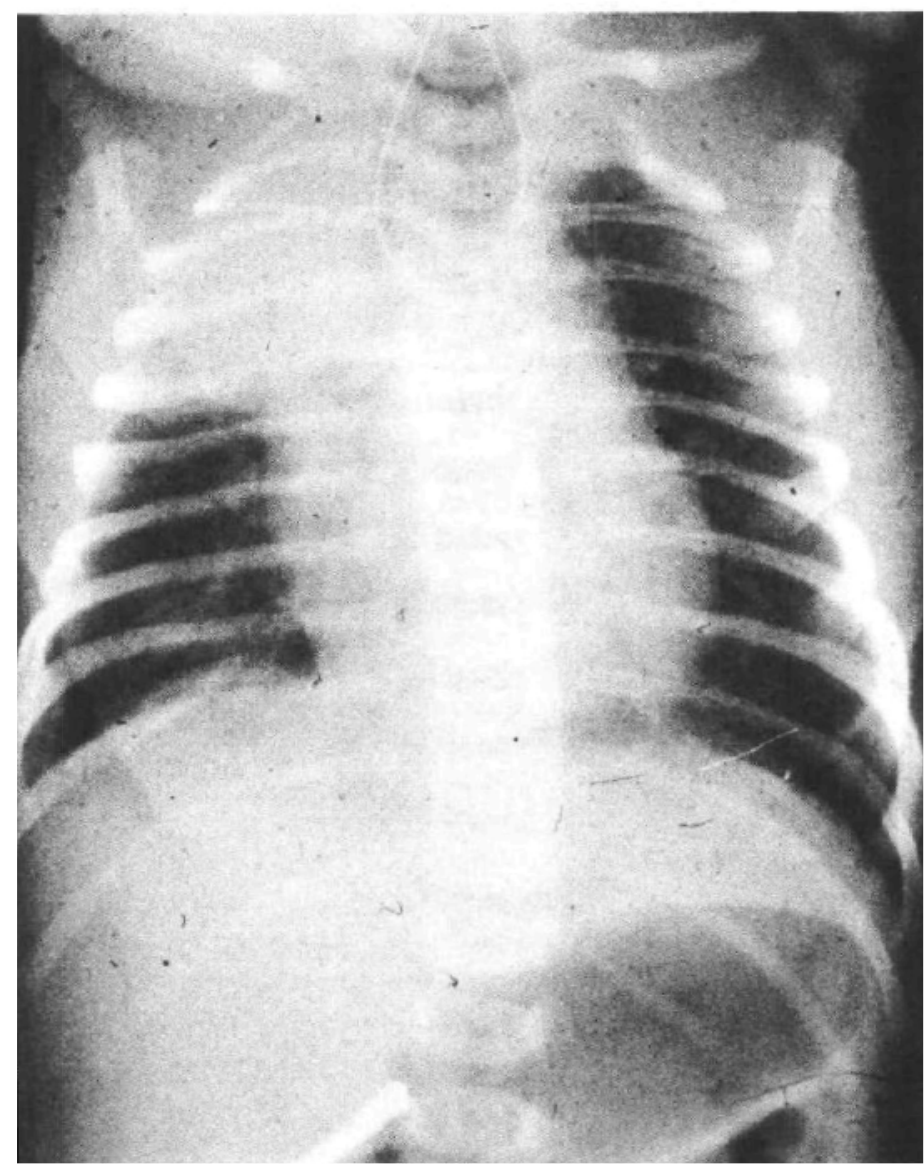

Ficure 2. Chest $x$-ray showing radiopaque catheter lodged in the proximal oesophageal segment.

depletion is unusual with gastro-intestinal obstruction at the level of the oesophagus. The ages at operation were comparable in two series. In the first series 74 per cent and in the second 70 per cent were operated on within 48 hours of birth (Table VIII).

The surgical procedure of choice is ligation of the fistula and primary oesopha-

TABLE VIII

age at the Time of Operation

\begin{tabular}{lcc}
\hline & $1959-1963$ & $1964-1968$ \\
\hline Under 12 hours & 12 & 9 \\
$12-24$ hours & 22 & 21 \\
$24-48$ hours & 37 & 28 \\
$48-72$ hours & 13 & 10 \\
$3-5$ days & 15 & 8 \\
One week & 5 & 7 \\
\hline
\end{tabular}


geal anastomosis by a transpleural or extra pleural approach as soon after birth as is practical. Premature babies, particularly those $1,800 \mathrm{gm}$ (Group C1), ${ }^{2}$ or babies with severe pulmonary complications or life-threatening congenital anomalies or both (Group C2), ${ }^{2}$ may not tolerate immediate complete correction and the procedures should then be staged. ${ }^{\circ}$ In these cases if the patient's condition permits a gastrostomy or gastrostomy-plus-ligation of the fistula is performed first. Gastrostomy reduces the risk of gastric juice refluxing into the lungs. A few days later when the baby's condition has improved definitive repair is undertaken. If ligation of the fistula only is possible, then gastric feedings are given until the babies' condition allows oesophageal anastomosis.

TABLE IX

Surgtcal Procedures

\begin{tabular}{|c|c|c|c|c|}
\hline & \multicolumn{2}{|c|}{$1959-1963$} & \multicolumn{2}{|r|}{$1964-1968$} \\
\hline & No. & $\begin{array}{l}\text { Percentage } \\
\text { of Total }\end{array}$ & No. & $\begin{array}{c}\text { Percentag } \\
\text { of Total }\end{array}$ \\
\hline $\begin{array}{l}\text { Primary Repair } \\
\text { (trans-thoracic } \\
\text { ligation of fistula } \\
\text { and oesophageal } \\
\text { anastomosis) }\end{array}$ & 87 & 83 & 49 & 59 \\
\hline Staged Procedures & 14 & 13 & 27 & 32 \\
\hline$\underset{\text { Figation } H-T y p e}{\text { Fistula }}$ & 3 & & 7 & $\begin{array}{l}\text { (3 cervical } \\
4 \text { trants- } \\
\text { thoracic) }\end{array}$ \\
\hline
\end{tabular}

In the second series 49 of the patients underwent total primary repair and of these 43 or 92 per cent survived. When the fistula was of the H-type 5 of 7 or 71 per cent survived ligation.

In the first series 14 or 13 per cent of patients underwent staged procedures. In the second series 27 or 32 per cent underwent staged procedures, a procedure more than double that in the first series.

The group of 27 patients in the second series treated by staged procedures included 24 classified as Group $\mathrm{C}$, a group numbering 36 in the series. In 10 of the 27 it was not feasible to complete the oesophageal anastomosis. None of the 10 survived. It is noteworthy that of the 16 survivors in the C2 group, 11 had undergone staged repair.

\section{ANaEsthetic Management}

The anaesthetic management has changed since the first series was reported. There have been continuing efforts to reduce the preoperative morbidity by meticulous attention to the details of management and monitoring of vital signs.

A percutaneous infusion route is established and 5 per cent glucose in 0.2 per cent saline is administered at a rate of about $5 \mathrm{ml} / \mathrm{kg} / \mathrm{hr}$ using a "mini-drip". A three-way stopcock is placed near the infusion site to allow accurate administration of blood and drugs without excess fluid administration. Atropine is administered in a dose of $0.02 \mathrm{mg} / \mathrm{kg}$. 
Induction follows awake tracheal intubation and tracheo-bronchial suction. Intubation of the fistula must be avoided. On two occasions in the first series, air entry could not be heard and it was necessary to withdraw and re-insert the tube several times. Keeping the bevel of the tube posterior during intubation may ininimize the risk of intubating the fistula.

Anaesthesia is induced with nitrous oxide and oxygen. Manually controlled ventilation must be cautiously attempted before administrating a muscle relaxant. Inflation of the stomach can be detected by a stethoscope placed on the abdomen and may be minimized with a snug abdominal binder. Should inflation of the stomach through the fistula occur, the patient may be allowed to breathe spontaneously with careful manual assistance, using supplementary halothane*, until the chest is opened. The fistula is ligated as soon as possible. If continued spontaneous ventilation is not feasible because of the condition and position of the patient, deflation of the stomach by percutaneous needle or even gastrostomy may be necessary before the thoracotomy. Although gastric inflation was not reported in either of our series, it has occurred, during the past year, in two patients not included in the review.

The endotracheal tube with plug and chain connector should be the largest size which can be easily inserted hrough the glottis and subglottic region to facilitate tracheo-bronchial suctioning. Under no circumstance must any force be applied to introduce the tube. In fact, a small leak around the tube during controlled ventilation is desirable. The narrowest portion of the infant's airway is at the cricoid ring, not at the glottis. The average size of Portex tube used was 3.5 $\mathrm{mm}$ with a range of 2.5 to $4.0 \mathrm{~mm}$ and of Cole tube was $14 \mathrm{~F}$ with a 10-16 range. Postoperative subglottic oedema was not reported in either series.

Our preference now for maintenance anaesthesia is nitrous oxide and oxygen, with small doses of D-tubocurarine. However, during both of the series reported this technique was used in just over 50 per cent of the cases with halothane or methoxylluranet being used in the others. The average total dose of D-tubocuraine used was $2 \mathrm{mg}$. In cases where dilute Succinylcholine $(2 \mathrm{mg} / \mathrm{ml})$ was used the average total dose was $16-25 \mathrm{mg}$.

Ventilation is manually controlled, using a modified Ayre's T-piece with an open ended bag, in order that the anaesthetist can detect and compensate for changes in compliance.

The retracted upper lung must be periodically re-inflated during the procedure and tracheo-bronchial suction performed when required to remove blood and secretions. This need was illustrated in a case of persistent lobar atelectasis reported in the first series. Care must be taken during suctioning as accidental extubation, reported in 3 cases in the combined series, is a real hazard.

Blood pressure is monitored using an infant blood pressure cuff and a Collin's oscillometer, ${ }^{10}$ though recently the Doppler ${ }^{11}$ flow meter has been found to be the most satisfactory method of continuous blood pressure monitoring in all our neonatal cases. A cardioscope is attached in all cases.

"Fluothane Ayerst, McKenna \& Harrison Limited, Montreal, Quebec.

†Penthrane Abbott Laboratories Limited, Montreal, Quebec. 
The placing of a small stethoscope in the dependent axilla to monitor the cardiac rate and rhythm and the ventilation of the dependent lung is of particular importance. Enthusiastic retraction of the upper lung may kink the main bronchus to the dependent lung and dislodge secretions from a diseased upper lung into the dependent part of the bronchial tree. Hence the absolute necessity for continuous monitoring of the air entry to the dependent lung. This retraction clearly resulted in a cardiac arrest (resuscitated) in one case in each of the reported series and was probably the contributory cause in the cardiac arrests which occurred during the primary repair in an additional 3 cases in the first series.

Temperature control is important. The neonate may respond to the cooling effect of his environment with increased oxygen consumption and metabolic acidosis, even when normothermia is maintained. ${ }^{12}$

The operating room temperature is raised to $75^{\circ} \mathrm{F}$, and an infrared overhead lamp is directed toward the patient as he is placed on a warming blanket. A warmed solution is used for surgical preparation. Efforts should be made to humidify inspired gases. Despite these precautions, significant hypothermia occurred in at least 2 patients.

Blood loss is determined by weighing of sponges and measuring the suction loss in a graduated flask. The range of blood replacement was from 10 to $200 \mathrm{ml}$ with an average of $68 \mathrm{cc}$ in the first series and $42 \mathrm{cc}$ in the second series. This was equivalent to approximately 30 per cent of the estimated blood volume.

Metabolic acidosis and hypoglycaemia are potential problems, particularly when relatively large volumes of blood are administered. ACD blood is buffered by the addition of $14-15 \mathrm{mEq}$ of sodium bicarbonate to each $500 \mathrm{ml}$ unit to prevent metabolic acidosis. Increments of $\mathbf{1 5}$ per cent glucose solution are administered to prevent hypoglycaemia.

\section{Postoperative Management}

Postoperative care must be directed to the prevention and management of pulmonary complications. Skilled nursing care is extremely important and the facilities of a fully-equipped neonatal unit are essential for the best results. At present, these cases are cared for postoperatively not in the postanaesthetic room, but in the neonatal unit at our hospital.

The pharynx is suctioned with a soft catheter which is measured and the length clearly marked so that the anastomotic site is not damaged.

If ventilatory problems occur in the immediate postoperative period, a nasotracheal tube is left in place to facilitate suctioning and ventilatory support. An awake reinsertion of the endotrotracheal tube may be necessary to facilitate tracheobronchial suctioning in some cases. In the second series, 12 patients required postoperative ventilatory support and half survived. In 4 of these, the nasotracheal tube had been left in place at the end of the procedure. The remaining 8 had to be reintubated. In the first series, 12 patients had also required postoperative ventilatory support.

The postoperative complications occurring in the second series are listed in Table X. 
TABLE $\mathrm{X}$

Postoperative Complications - 1964-1968

\begin{tabular}{lrr}
\hline & No. cases & Survivors \\
\hline Respiratory Complications & 24 & 13 \\
Pneumonia & 12 & 7 \\
Atelectasis & 4 & 4 \\
Pneumothorax & 3 & 2 \\
Tracheostomy tube dislodged & 2 & 0 \\
Respiratory arrest & & \\
A nastomosis Leak & & \\
Empyema and pneumothorax & 1 & 0 \\
Empyema & 2 & 0 \\
Recurrent fistula & 4 & 2 \\
Congestive Heart Failure & 5 & 1 \\
Convulsions & 3 & 3 \\
Hypocalcaemia & 6 & 5 \\
Septicaemia & 1 & 0 \\
Hyperbilirubinaemia & 3 & 3 \\
Oesophageal stricture & 19 & 19 \\
\hline
\end{tabular}

\section{MORTALITY}

Table XI shows the time at which death occurred. In the first series 21 or 55 per cent of the deaths occurred within 48 hours of the induction of anaesthesia and 13 or 34 per cent within 24 hours. It is important to note in the second series only 5 or 27 per cent of deaths occurred within 48 hours and 2 or 11 per cent within 24 hours.

TABLE XI

TIME OF DEATH

\begin{tabular}{lcc}
\hline & $1959-1963$ & $1964-1968$ \\
\hline ln the operating room & 1 & 0 \\
Within 24 hours & 12 & 2 \\
Within 24-48 hours & 8 & 3 \\
48 hours to one week & 10 & 3 \\
Over one week & 7 & 10 \\
Number of deaths (mortality) & $38(36.5 \%)$ & $18(21.7 \%)$ \\
\hline
\end{tabular}

The causes of death are summarized in Table XII. Pulmonary complications are the most common cause of death in both series.

In the first series cardiac arrest occurred in the operating room on 6 occasions. Of the 4 that occurred during the primary repair, 1 was successfully resuscitated, 1 died in the operating room, and 2 were resuscitated but died in the early postoperative period, Cardiac arrests occurred in 2 children during subsequent colostomy for imperforate anus. Both died in the early postoperative period. However, in the second series cardiac arrest occurred on only one occasion in the operating room following an acute ventilatory problem and was successfully resuscitated. The fatal cardiac arrests in the second series were all terminal events following respiratory failure or unrelenting cardiac failure, and so these cases are listed as the complication which precipitated the terminal arrest. 
TABLE XIY

Cause of Death

\begin{tabular}{lcc}
\hline & $1959-1963$ & $1964-1968$ \\
\hline Pulmonary complications & 27 & 11 \\
Congestive heart failure & 4 & 4 \\
Liver abscess & 1 & 0 \\
Perforated gastric ulcer & 1 & 1 \\
Tracheostomy tube dislodged & 0 & 2 \\
Subdural haemorrhage with & & 0 \\
postoperative aspiration & 1 & 0 \\
Cardiac arrest & 5 & \\
\hline
\end{tabular}

\section{SUMmaRY AND CONCLUSIONS}

The overall survival rate in cases undergoing surgical correction of tracheooesophageal fistula at The Hospital for Sick Children, Toronto, has improved from 63.5 per cent in the 104 cases treated during the 1959-1963 period, to 78.3 per cent in the 83 cases treated during the 1964-1968 period. Cases in the two 5-year series were comparable with respect to the types of anomaly, the incidence of prematurity and associated congenital anomalies, and the age at operation. In the second series a higher incidence of pulmonary complications was recorded. In the second series the survival rate was 100 per cent in those cases over 1,800 gms without significant associated anomalies and/or pulmonary complications. There was also 100 per cent survival rate in group $B_{2}$.

Review of the survival rates indicates that the fate of many infants with tracheooesophageal fistula is probably determined by prematurity, associated anomalies and/or pulmonary complication before operation is undertaken. ${ }^{12}$ However, the 1964-1968 survival rate indicates that efforts to improve the anaesthetic and surgical management during pre-, per-, and post-operative periods can increase survival even in premature babies. The anaesthetic and postoperative management techniques have improved with more meticulous attention to details of the techniques of management and monitoring of the neonatal patient. The most obvious change in surgical management was the increased number of staged procedures in poorrisk patients. The overall improvement in management of these cases is also reflected in the markedly reduced proportion of the deaths which occur during the first 48 hours postoperatively.

In conclusion, babies undergoing general anaesthesia for surgical correction of tracheo-oesophageal fistula, who weigh over $1,800 \mathrm{gm}$ and are without severe associated anomalies and/or pulmonary complications (Group $A_{1}, B_{1}$ ) and those of a higher birth weight with moderate pneumonia and a less severe congenital anomaly (Group $B_{2}$ ), can be reasonably expected to survive.

\section{ACKNOWLFDGMENTS}

The authors acknowledge with gratitude the assistance of Dr. D.J. Steward, Chief of Anaesthesia and Dr. C.A. Stephens, Chief of General Surgery at the Hospital for Sick Children, Toronto, for advice in preparation of the manuscript. 


\section{RÉsUMÉ}

Le taux de survie globale des cas subissant une chirurgie correctrice pour fistule trachéo-pesophagienne ou Sick Children de Toronto, est passé de 63.5 pour cent sur 104 cas traités au cours des années 1959 a 1963 à 78.3 pour cent les 83 cas traités au cours de la période allant de 1964-1968. Tous les patients opérés au cours de ces deux périodes de 5 ans étaient comparables en regard du type d'anomalie, lincidence de la prématurité, la présence d'anomalies congénitales associées et lâge au moment de lopération. Dans le deuxième groupe, une incidence plus elevée de complications pulmonaires fut observée. Dans ce même groupe, le taux de survie fut de 100 pour cent chez le patients au-dessus de $1800 \mathrm{gms}$ ne présentant pas d'anomalies associées importantes et/ou de complications pulmanaires. Il y eut également 100 pour cent de survie chez les patients du groupe $\mathbf{B}_{\mathbf{2}}$.

Une revue des taux de survie laisse croire que le sort de plusieurs enfants porteurs de fistule trachéo-oesophagienne est probablement en rapport avec la prématurité, les anomalies associées et/ou une complication pulmonaire déjà présente au moment de l'opération. Cependant, le taux de survie des années 1964-1968 indique que les efforts en vue d'anéliorer les techniques anesthésiques et chirurgicales en pré, per et post-opératoire peuvent améliorer le taux de survie mème chez les bébés prématurés. Les techniques anesthésiques et post-opératoires se sont améliorées lorsqu'on a accordé une attention plus particulière aux détails des soins et monitoring du patient prématuré. Le changement le plus manifestement évident concernant la technique chirurgicale fut l'augmentation du nombre d'interventions à diverses étapes chez les patients considérés comme des mauvais risques. L'amélioration globale des soins de ces cas se réfète également dans la diminution marquée des décès survenant dans les 48 heures post-opératoires.

En conclusion, les enfants subissant une anesthésie pour correction chirurgicale de fistule trachéo-oesophagienne, qui pèsent plus de 1800 grs et ne présentant pas d'anomalies associées importantes et/ou de complications pulmonaires (groupe $A, B_{1}$ ) et ceux d'un poids à la naissance plus élevé, avec pneumonie légère et une anomalie congénitale peu importante (groupe $\mathrm{B}_{2}$ ), ont des chances résonnables de survie.

\section{REFERENCES}

1. Jounston, A.E. \& Conn, A.W. The anaesthetic management of tracheo-esophageal fistula: A review of five years' experience. Can. Anaes. Soc. J. 13: 28 (1966).

2. Watezston, D.J., BonfaM Cantra, R.E., \& ABEndirn, E. Oesophageal atresia: Tracheoesophageal fistual. A study of survival in 218 infants. Lancet 1: 819 (1962)

3. KENNEDY, R.L. \& STOELTING, V.K. Anaesthesia for surgical repair of esophageal atresia and tracheo-esophageal fistula. Can. Anees. Soc. J. 5: 132 (1958).

4. Wyant, G.M. \& CAAM, R.W. The management of infants with tracheo-esophageal fistula. Can. Anaes. Soc. J. 10: 93 (1963).

5. JACOBS, R.G. \& PAPPER, E.M. Anaesthetic management of congenital atresia of the esophagus and tracheo-esophageal fistula: A review of seven years experience and 72 cases. New York State J. Med. 59: 995 (1959).

6. WrToN, T.M. Anaesthesia for esophageal surgery in infants and children. Anaes. Analg. (Cleve) 31: 267 (1952).

7. ZINDLERA, M. \& VAN N. DemMang, $M$. The anaesthetic management of infants for the surgical repair of congenital atresia of the esophagus with tracheo-esophageal fistula. Araes. Analg. (Cleve) 32: 180 (1953). 
8. HoLder, T.M. A AsfCRAFT, K.W. Esophageal atresia and tracheo-esophageal fistula. Ann. Thorac. Surg. 9: 445 (1970).

9. HoLder, T.M. MCDONaLd, V.G. Jn, \& Woolsey, M.M. The prenature or critically ill infant with esophageal atresia: Increased success with a staged approach. J. Thorac. Cardiovasc. Surg. 44: 344 (1962).

10. SLOAN, I.A. An improved infant blood pressure cuff. Can. Anaes. Soc. J. I4: 59 (1967).

11. Waltermate, C.L. \& Preuss, D.D. Determination of blood pressure in low-flow states by the Doppler technique. Angesthesiology, p. 978, Jan. (1971).

12. Ross Conference on Paediatric Research: Thermo Regulation of the Newly Born. Supplement No. 2 .

13. ST:PHENS, C.A., Mustard, W.T, \& Simpson, J.S. Congenital atresia of the esophagus with tracheal-esophageal fistula. Surg. Clin. North Am., December, 1465 (1956). 